\title{
Article \\ Influence of Nanoparticles on the Degradation Processes of Ester-Based Transformer Insulation Systems
}

\author{
Daniel Pérez-Rosa * (D), Belén García *(i) and Juan Carlos Burgos *(i)
}

Electrical Engineering Department, Universidad Carlos III de Madrid, 28903 Getafe, Madrid, Spain

* Correspondence: daperezr@ing.uc3m.es (D.P.-R.); belen.garcia@uc3m.es (B.G.); jcburgos@ing.uc3m.es (J.C.B.)

check for

updates

Citation: Pérez-Rosa, D.; García, B.;

Burgos, J.C. Influence of

Nanoparticles on the Degradation

Processes of Ester-Based Transformer

Insulation Systems. Energies 2022, 15,

1520. https://doi.org/10.3390/

en15041520

Academic Editors: George

Avgouropoulos and Dmitri A.

Bulushev

Received: 17 December 2021

Accepted: 11 February 2022

Published: 18 February 2022

Publisher's Note: MDPI stays neutral with regard to jurisdictional claims in published maps and institutional affiliations.

Copyright: (c) 2022 by the authors. Licensee MDPI, Basel, Switzerland. This article is an open access article distributed under the terms and conditions of the Creative Commons Attribution (CC BY) license (https:// creativecommons.org/licenses/by/ $4.0 /)$.

\begin{abstract}
The use of nanofluids as dielectric liquids for transformer insulation has been widely investigated during the last decade. A number of authors have performed extensive studies on liquids produced from different types of nanoparticles and base fluids, providing evidence of their good dielectric properties. Nevertheless, nanodielectric fluids are still at the research stage, and they are far from being a solution that can be applied to real transformers. One of the aspects that might be clarified is their compatibility with the rest of the materials present in the transformer and their behavior throughout the life of the equipment. This paper studies the aging process of cellulose impregnated with an ester-based nanofluid and compares it with the process that takes place when the impregnation liquid is a natural ester. Accelerated aging experiments were performed, and physical and chemical characterization of the process with several analytical techniques was carried out. The mechanical degradation of the cellulose was studied in terms of tensile strength, and the evolution of moisture in the paper and oil was monitored throughout the aging process. The study was completed with FTIR and XPS tests aimed at studying the chemical changes of the materials during the aging process. The experimental results suggest that the degradation rate of the cellulose is not significantly affected by the presence of nanoparticles. However, the XPS study revealed that the chemical reactions involved in the degradation processes of both types of insulation might differ. Several mechanisms are proposed in this work.
\end{abstract}

Keywords: power transformers; dielectric nanofluids; oil-paper insulation; cellulose; aging; natural ester; tensile strength; FTIR; XPS

\section{Introduction}

The insulation system is one of the most important parts of a power transformer; failures in this system may lead to serious problems in transformer operation that could compromise the stability of the power system [1,2]. The insulation of a transformer mainly consists of kraft paper and pressboard [3], along with the liquid insulation that fills the transformer tank and impregnates the solid insulation. The most commonly used liquid insulation is mineral oil (MO), which is derived from petroleum, although in recent years, natural and synthetic esters are becoming popular for transformer insulation purposes.

Another innovation that has recently been explored is the possibility of using nanofluids (NF) as liquid insulation in transformers. These liquids are produced by adding small amounts of nanoparticles (NP) to a base fluid that can be an MO or a natural or synthetic ester. NFs have attracted substantial attention, as they exhibit an improvement in some key thermal or dielectric properties [4-6], which could lead to the design of smaller and more efficient transformers in the future [7].

Several authors have conducted studies using different NPs dispersed in several base fluids, observing improvements in AC breakdown voltage [8-10], thermal properties [11] or even an improvement in the lightning impulse strength [12-14]

Despite of the large number of studies that have been published investigating the properties of NFs as liquid insulation for transformers, not so many works have been 
conducted to analyze how these NFs interact with other elements of the machine. If NFs were used inside a transformer, they would become part of a complex system in which one of the main components are the kraft paper and pressboard that compose the solid insulation of the transformer. The behavior of NF-cellulose insulation has been studied by a few authors. Some works have analyzed the morphology of the cellulose insulation when it is impregnated with NF [15-18]; in [18] the presence of NPs within the cellulose fibers was proven by studying the NF-impregnated kraft paper with microscopy techniques. Other authors have analyzed the dielectric properties of NF-cellulose composites for new and aged cellulose materials, reporting a certain improvement in the breakdown voltage of the paper under alternating current (AC) and impulse waveforms [19]. The influence of the NPs on the dielectric response of the oil-paper insulation was researched by Potao et al. [20], Liao et al. [17], and Pérez-Rosa et al. [21], who observed a significant variation in the values of the permittivity and the dielectric losses of these materials. Finally, some publications have investigated the aging process of cellulose in presence of NFs, which is the objective of this work as well.

Cimbala et al. [22] studied the dielectric response of NF-paper system insulation after a long aging process; they compared the results with those obtained with base oil and observed better behavior for the NF-based system when moisture from the environment or from the paper-liquid interface passes to the liquid insulation. They also observed the end of NF stability during the aging process, which led to the aggregation of the NPs. The surface discharge properties of aged kraft papers impregnated with MO and NF were studied by Swati et al. [23], who concluded that NFs tend to accumulate a higher amount of charge and dissipate it more slowly, although the authors did not observe chemical changes in the FTIR spectrum of the samples. Another aspect that has been used to evaluate the aging process in the presence of NFs is the tensile strength of aged paper samples. In [24], the authors observed a higher tensile strength for samples of kraft paper impregnated with NF. In another study, Maharana et al. [25] evaluated in depth the physico-chemical properties of aged NF-impregnated paper, considering different NFs. Finally, Ibrahim et al. [26] carried out accelerated aging tests of cellulose in the presence of an NF prepared with $\mathrm{ZnO}$ NPs and MO, and studied the change in the dielectric properties of cellulose and the moisture content in oil throughout the aging process.

In previous works, the authors studied how NPs interact with cellulose with a morphological analysis [18] through the analysis of the dielectric response of NF-impregnated kraft paper [21], confirming that when cellulose is impregnated with NF, there is an interaction between NPs and cellulose fibers that modifies some properties of the solid insulation. In the present paper, the study is extended to the evaluation of the impact of NPs in the thermal aging process of cellulose.

The main objective of this paper is to gain insight into the aging process of kraft paper impregnated with an ester-based NF. For this purpose, several physico-chemical techniques have been used to identify differences in the aging processes of paper impregnated with NF and with natural ester (NE). The techniques used to characterize the aging processes of the samples were the tensile strength test, to determine the degree of mechanical degradation of the insulation, and Karl Fischer titration, to characterize the evolution of the moisture content of the paper and oil throughout the tests. Additionally X-ray Photoelectron Spectroscopy (XPS) and Fourier Transform Infrared Spectroscopy (FTIR) were used to identify how NPs interact with the cellulose structure during the aging process. Aging of paper samples was carried out at $110^{\circ} \mathrm{C}$, in order to guarantee adequate stability of the NF during the entire test time. The tests were carried out at the end of the aging period of the samples. The experiments provide a realistic view of the effect of the NPs on the aging process under real transformer working conditions

\section{Experimental Procedure}

As explained before, the main objective of the experimental study was to evaluate the effect of the NPs on the aging process of paper-impregnated insulation. Two kinds 
of samples were subjected to accelerated aging tests and further investigation: samples composed of kraft paper impregnated and immersed in an NE, and samples of kraft paper impregnated and immersed in an NF with the same NE as base fluid.

\subsection{Preparation of the Samples}

The commercial NE Bioelectra was used as the base fluid to prepare the NF characterized in this work. The same liquid was used to prepare the control samples that were used to compare results with those of NF-based samples. Bioelectra is manufactured by the company Repsol (Repsol, Madrid, Spain), and it is composed of at least $99 \%$ vegetable oils, mainly obtained from sunflower seeds, with no silicon and a total absence of halogen compounds.

The NPs used in the NF were $\mathrm{Fe}_{3} \mathrm{O}_{4}$, with an approximate diameter of $10 \mathrm{~nm}$. The NPs were supplied by the company Magnacol Ltd. (Newtown, UK) as an NP suspension in a hydrocarbon base at a concentration of $60 \%$ by weight (i.e., $600 \mathrm{~g}$ of NP in $1 \mathrm{~kg}$ of dispersion).

NFs were prepared by mixing the NE with small amounts of $\mathrm{Fe}_{3} \mathrm{O}_{4}$ dispersion; the concentration of NP in the obtained NF was $0.1 \mathrm{~g} / \mathrm{L}$. For the dispersion of the NPs in the base fluid, ultrasound stirring was used. Batches of $500 \mathrm{~mL}$ of NE and NPs were subjected to ultrasound treatments with wave intensity $268 \mathrm{~W} / \mathrm{cm}^{2}$ for two hours, with alternating agitation periods of $30 \mathrm{~s}$ and pauses to prevent excessive heating of the mixture. The prepared NFs presented fair stability at the temperature considered for the accelerated aging tests $\left(110^{\circ} \mathrm{C}\right)$ for at least 8 weeks [27].

The cellulose insulation tested in the study was transformer kraft paper of grammage $0.75 \mathrm{~g} / \mathrm{cm}^{3}$ and thermal class $105^{\circ} \mathrm{C}$.

The aging vessels were $100 \mathrm{~mL}$ crystal vials with silicone septa.

In order to allow a statistical analysis of the results obtained and to guarantee a sufficient quantity of samples to perform the tests, five strips of kraft paper with a total mass of $0.03 \mathrm{~g}$ were introduced in each vial, as can be seen in Figure 1.

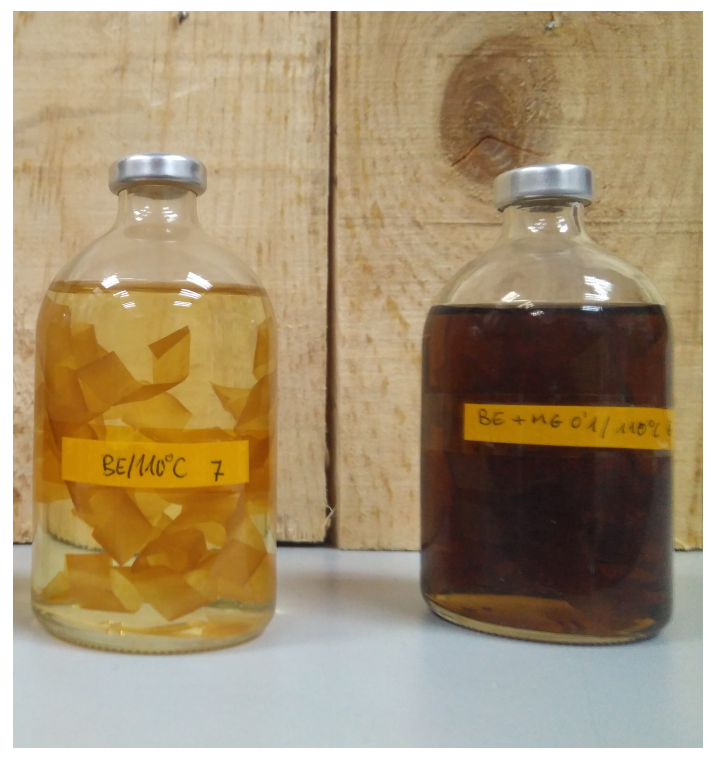

Figure 1. NF and NE aging test vials.

The vials with the paper samples were dried in two stages: first they remained under vacuum at $60^{\circ} \mathrm{C}$ for $48 \mathrm{~h}$, then, the temperature was raised to $80^{\circ} \mathrm{C}$ for $2 \mathrm{~h}$. The NE and the $\mathrm{NF}$ were also preconditioned before filling the testing vials. The process of fluid drying was also performed in a vacuum oven, keeping the fluids at $60^{\circ} \mathrm{C}$ for $48 \mathrm{~h}$.

Once the paper and the two fluids were conditioned, the aging vials were filled with $\mathrm{NE}$ or NF and sealed with silicone septa. Then, the vials were kept at room temperature 
for 2 days to allow the samples to stabilize. After the stabilization process, the vials were treated by bubbling nitrogen in the NE or NF for $5 \mathrm{~min}$. This nitrogen treatment was used to avoid undesirable oxidation processes of the samples.

\subsection{Accelerated Aging Tests}

For the aging tests, the vials were kept in a temperature-controlled oven at a temperature of $110^{\circ} \mathrm{C}$ for 60 days. The selected test temperature was $110^{\circ} \mathrm{C}$ because the NE-based NF used in this work showed good stability at this temperature for at least 60 days [27], whereas for higher temperatures, stability problems were observed.

Throughout the tests, two vials, one of them filled with NE and the other one filled with NF, were removed from the oven after 3,6,11,16, 23, 30, 39, 50, and 60 days of testing. Additionally, samples of both specimens not subjected to aging were fully characterized, with these results considered as "fingerprints". The evolution of the two insulating fluids throughout the aging process can be seen in Figure 2. The coloration of the new NF samples was darker than that observed in the NE samples; this effect is due to the black color of the NP used in the experiment. The evolution of the colors as aging advanced was clear in both experiments. As can be seen, both types of fluids became darker due to the aging of the NE.

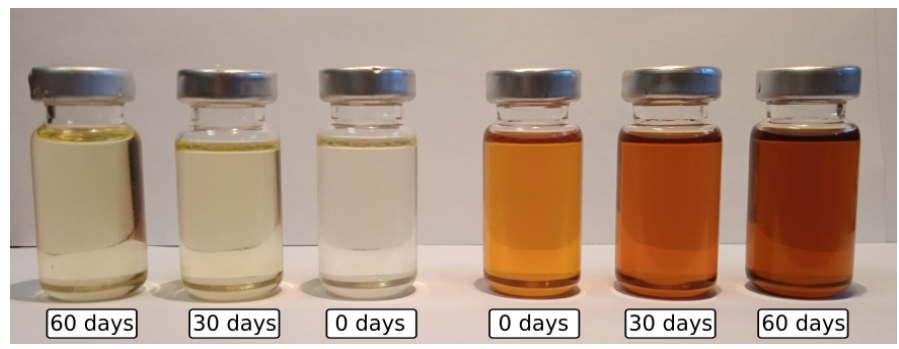

Figure 2. NF and NE aged fluid at several points of the accelerated aging test.

\subsection{Characterization of the Samples during the Aging Process}

The control variables that were considered during the aging tests were the tensile strength of the paper and the moisture content of paper and oil. Additionally, FTIR and XPS analysis were carried out on the samples to gain insight into the chemical structure of the materials.

\subsubsection{Tensile Strength Measurements}

Although the measurement of the polymerization degree (DP) is commonly acknowledged as a more reliable parameter to assess the aging condition of paper, that technique was not used in this work because NPs cannot be digested by the solvent that is used to perform DP measurements; thus, their presence might lead to erroneous results. For this reason, the aging condition of the paper samples at different stages of the aging tests was characterized by tensile strength measurements (TS).

The TS of the new and aged paper samples was evaluated using an MTC-100 Vertical Universal Tensile Tester (IDM). Five paper samples were prepared for each vial of the study by cutting paper strips $15 \mathrm{~cm}$ long. Each of these strips was tested with the tensile strength tester. The parameters used for the test were adjusted to the ASTM D828-97 standard [28]. Finally, the obtained TS data were statistically treated by discarding the outlier measures and calculating the average value of the remaining values, as will be discussed in the results section.

\subsubsection{Moisture Content of Oil and Paper}

The water content of the liquids and that of the cellulose samples was measured with the Karl Fischer (KF) method, using a KF Coulometer Methrom 831 combined with a KF Thermoprep oven. KF titration is a well-known method to determine water content in transformer oil, and it is also widely used to determine moisture in paper samples. In the 
case of the samples of this study, the use of a Thermoprep oven was required to avoid interference of the NPs in the KF measuring process.

\subsubsection{X-ray Photoelectron Spectroscopy}

X-ray photoelectron spectroscopy was performed on some of the samples included in the study to understand how the presence of NPs alters the chemical reactions involved in the degradation process, and to investigate the changes in the chemical bonds that are present in the oil-paper insulation as the aging process advanced.

The XPS measurements of the study, including the full width at half maximum (FWHM), were performed using an energy analyzer PHOIBOS 150 9MCD (SPECS GmbH) at the Institute of Catalysis and Petrochemistry of the Spanish Council for Scientific Research (CSIC), Spain.

\subsubsection{FTIR}

FTIR spectra were performed on cellulose samples to compare how NF and NE affect the degradation process of the cellulose immersed in each fluid during the accelerated aging.

The reason for using both XPS and FTIR to gain insight into the aging process is that each method is better suited to detect certain functional groups inside the molecules.

\section{Results and Discussion}

In this section, the results of the aforementioned tests on paper samples throughout the aging process are presented. Additionally, the evolution of the moisture content of the paper and fluid is analyzed in both cases: NF and NE.

\subsection{Tensile Strength}

Figure 3 shows the evolution of the TS of the kraft paper samples vs. aging time in days. It can be seen that the results are quite scattered. The kraft paper strips are thin and quite brittle, and tend to break inconsistently. It can be observed that the TS values measured for the samples of paper immersed in NF are slightly lower than those of the paper immersed in NE for the same aging times. As the aging advances, the results tend to approximate.

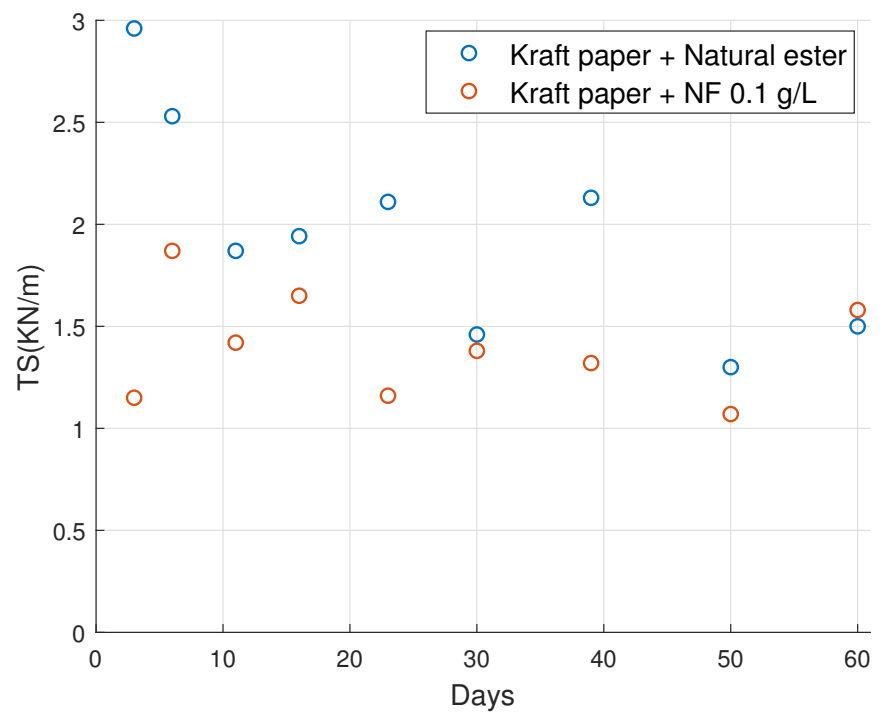

Figure 3. Tensile strength of paper vs. aging time.

The relationship between TS and DP of kraft paper was analyzed by Frimpong et al. [29], who reported that, in the first stage of the aging process (i.e., DP above 600), there is a drop in the paper DP that is not accompanied by a decrease of its TS [30]. This 
may be due to the fact that as long as the glucose chains are long enough, there is no clear impact on the mechanical properties of the material.

The aging process of the same type of kraft paper used in this experiment immersed in an NE was thoroughly analyzed by the authors in a previous work for longer aging times and at several temperatures [31]. The evolution of the DP measured in this experiment is shown in Figure 4.

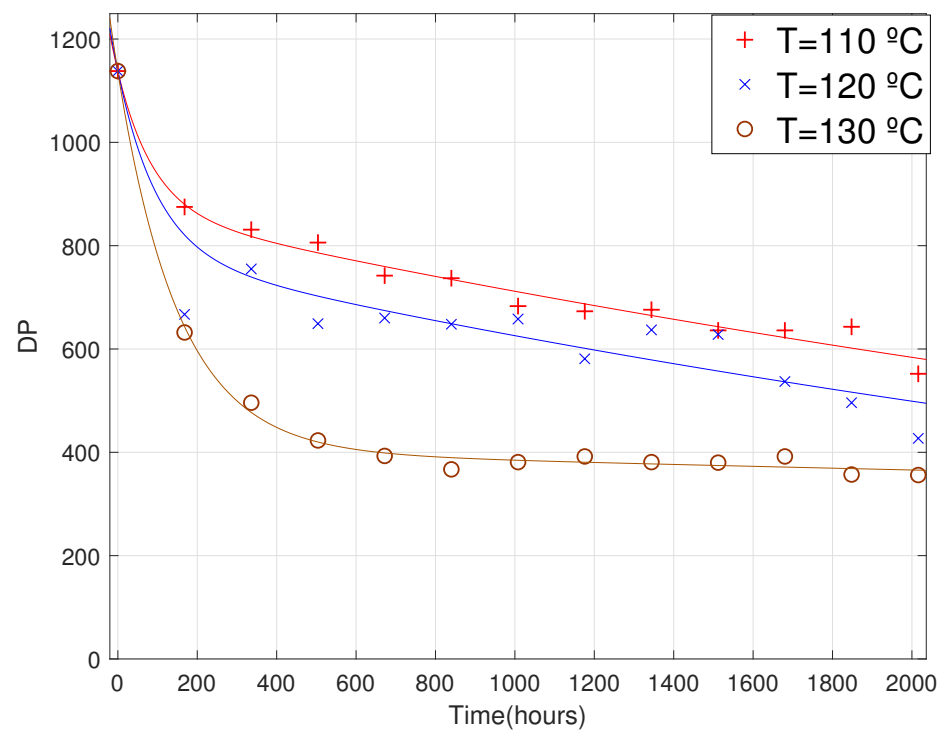

Figure 4. DP evolution vs. aging time of paper impregnated with NE. Taken from [31].

As can be seen, for the testing times of the last sample of the present study (60 days, $1440 \mathrm{~h}$ ), Figure 4 shows a DP of about 670 . The relation between DP and TS provided in Figure 4 justifies the behavior of the TS observed in our test; as the TS remains almost stable until the aging starts to degrade the cellulose fibers, the most important drop of this variable starts when the DP of the samples is below 600. Thus, for a DP of 670, only a slight decrease of the TS was observed. The main conclusion that can be extracted from the analysis of the TS of the NF-based and the NE-based samples is that the TS of both types of insulation behave similarly. Thus, a major effect of the NPs on the rate of loss of the mechanical properties of the cellulose can be discarded.

\subsection{Water Content Analysis}

Figure 5 shows the evolution of the moisture content of the NE and the NF during the aging process. Those measurements were taken on samples of fluid extracted from the aging vials.

It is possible to observe two well-differentiated stages in the aging process: before day 30 and after day 30. In the first stage, the moisture content present in the NE and the NF was almost the same. In the second stage, the trend of the moisture content in both fluids diverged: while the moisture in the NF kept rising until the end of the experiment, in the case of the NE it stabilized or even decreased.

The reduction of the moisture in the NE was reported before [31]. It is produced by a chain of chemical reactions that take place when the NE begins to degrade as a result of the aging process. The process of degradation of the fatty acids takes place through a hydrolysis reaction (Figure 6), which consumes water molecules. Thus, as the experiment advanced, the tendency was for a reduction of the moisture content of the dielectric fluid. 


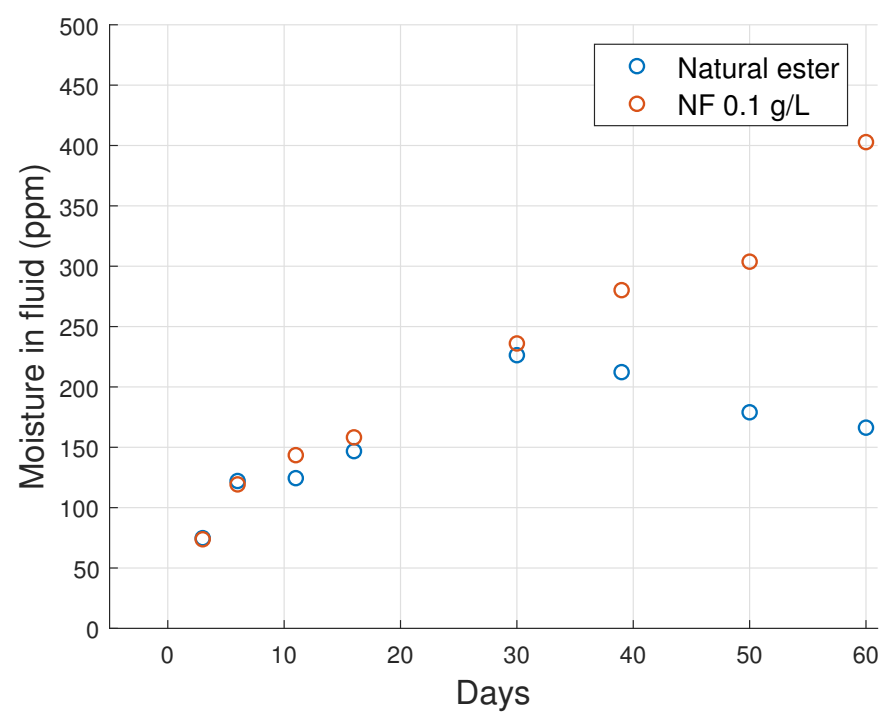

Figure 5. Moisture content in the fluid vs. aging time.

The presence of the free fatty acids produced in the hydrolysis reaction protects cellulose from degradation, since fatty acids are able to bind the hydroxyl groups of alcohols of cellulose chains, preventing the cellulose polymer from breaking down into shorter chains. This reaction is called transesterification and is illustrated in Figure 7. The transesterification reactions that occurred in the system NE-cellulose are shown in Figure 7.
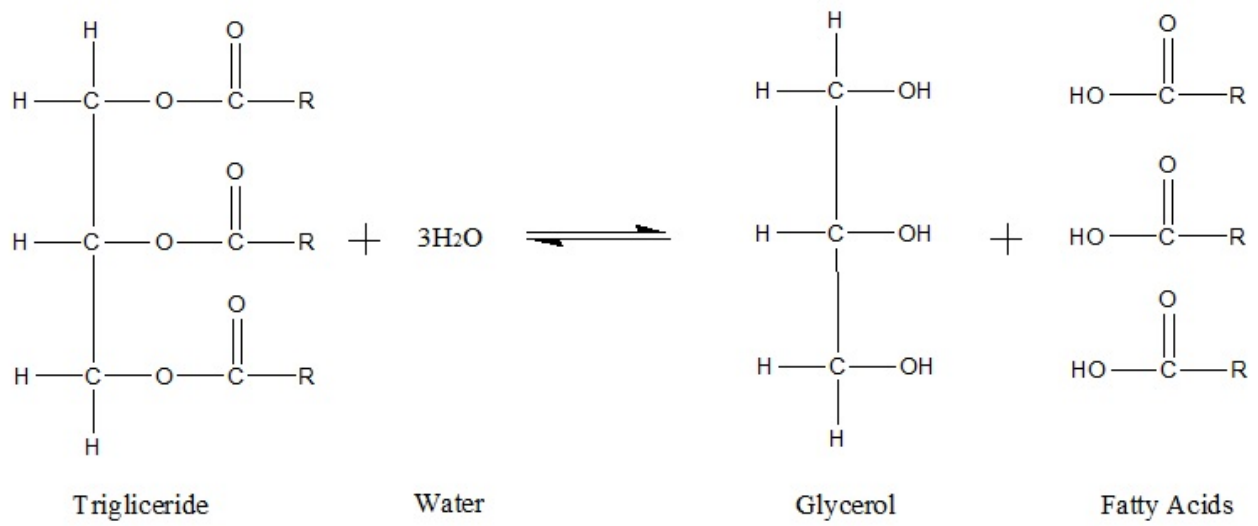

Figure 6. Hydrolisis of an NE.

In the case of the NF-immersed cellulose, the NPs seemed to interfere with the previously described chemical reactions, meaning that the amount of water consumed was less than in the case of the NE-immersed samples. This effect could be produced by the high capacity of the NPs to trap water; if the water molecules are bound to the NPs, they will not be available for other reactions such as the hydrolysis of ester. In addition, chemical bonds might have been created between the NPs and the hydroxyl groups of alcohols of the cellulose molecules [15], which would also inhibit the transesterification reaction that is typically involved in the aging process of cellulose in the presence of ester [31,32].

Figure 8 shows the results of the moisture tests on the aged paper samples as the experiment progressed. It is possible to see how moisture in the paper samples tended to stabilize at a value around $1 \%$ of RH. This final value is quite similar to the value at the beginning of the experiment. This effect, associated with the NE or NF moisture test, could reveal that dielectric fluid tends to accumulate most of the water molecules present in the system. This behavior has been observed previously by several authors $[19,31]$. 

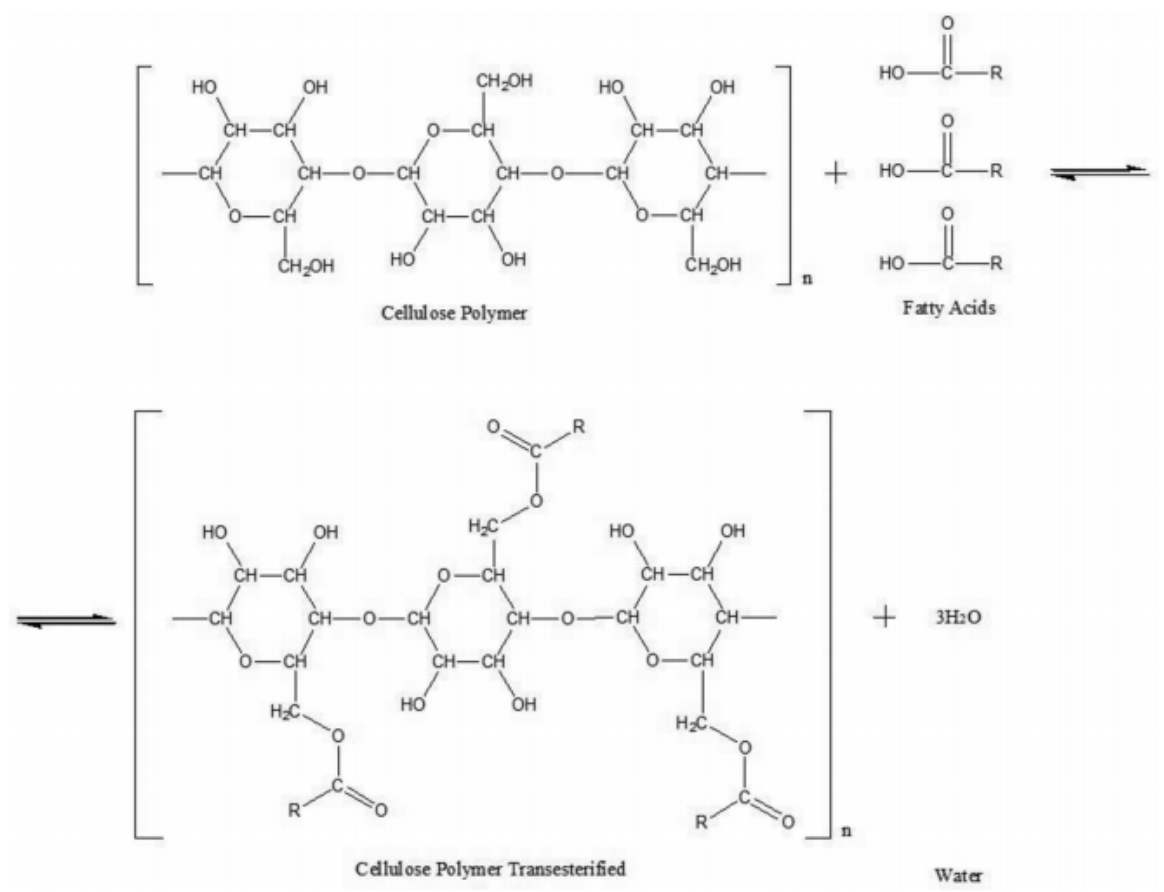

Figure 7. Transesterification reaction of cellulose.

\subsection{X-ray Photoelectron Spectroscopy Analysis of the Samples}

For a deeper analysis of the chemical reactions that take place in the different types of oil-paper insulation, an XPS analysis was carried out. Figure 9 shows the results of a high-resolution XPS spectroscopy performed on two kraft paper samples; the first sample was aged in presence of NE, and the second was aged in presence of NF. As can be observed, $\mathrm{O} 1 \mathrm{~s}$ and $\mathrm{C} 1 \mathrm{~s}$ peaks are shifted around $2-3 \mathrm{eV}$ from the results found by other authors [33]. The reason for this is that the samples are made of non-conductive materials. Since this study compares the width of the peaks of both samples, the conclusions are not affected by the shift.

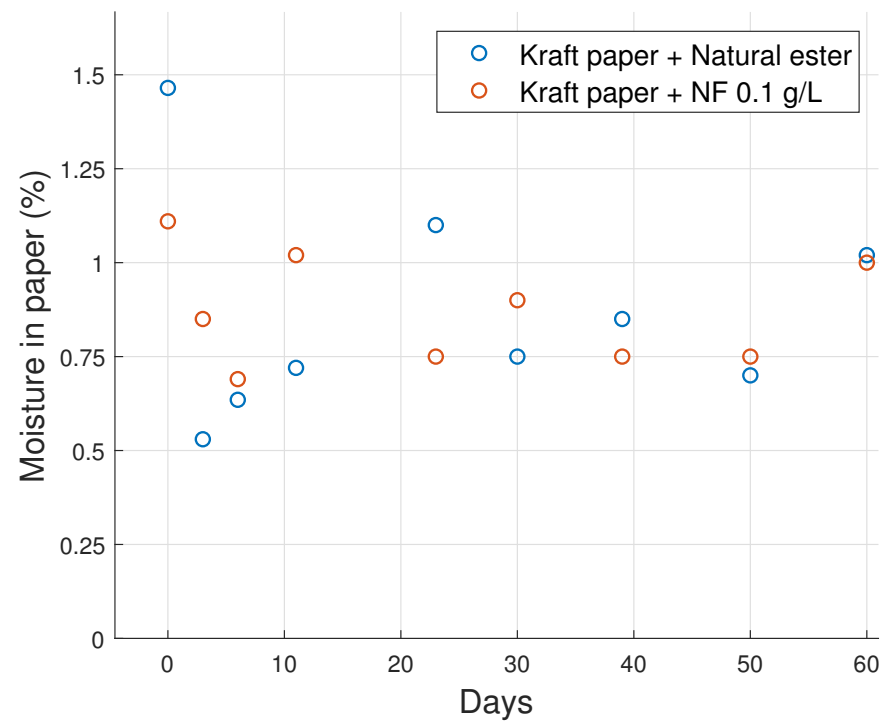

Figure 8. Moisture content in cellulose vs. aging time for NF- and NE-based insulation. 

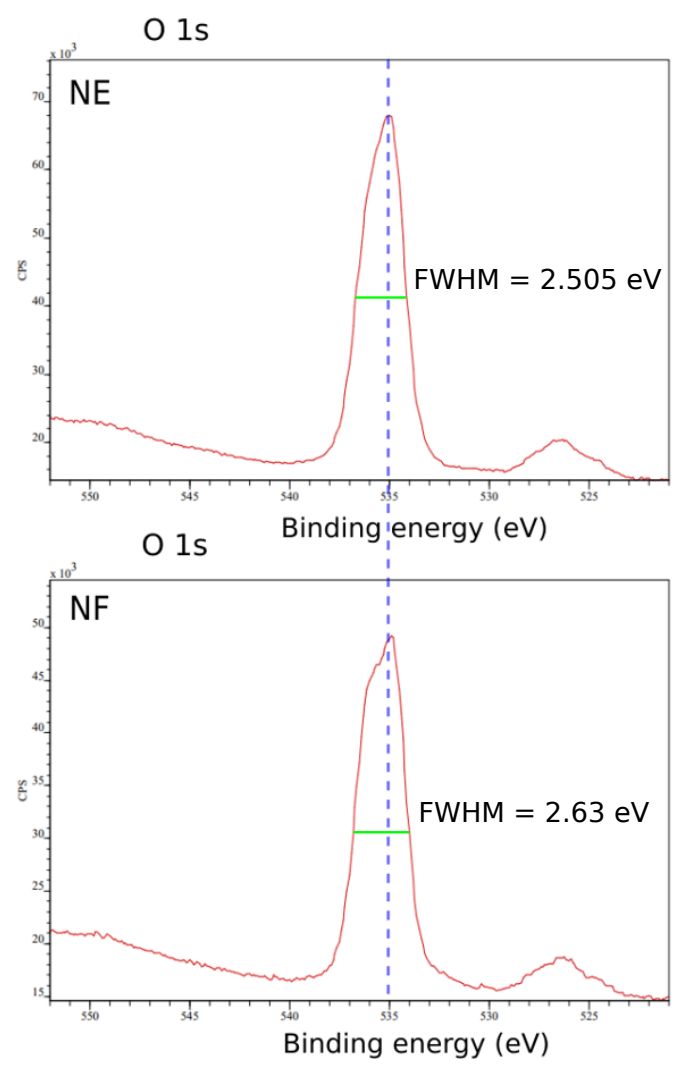

C 1s

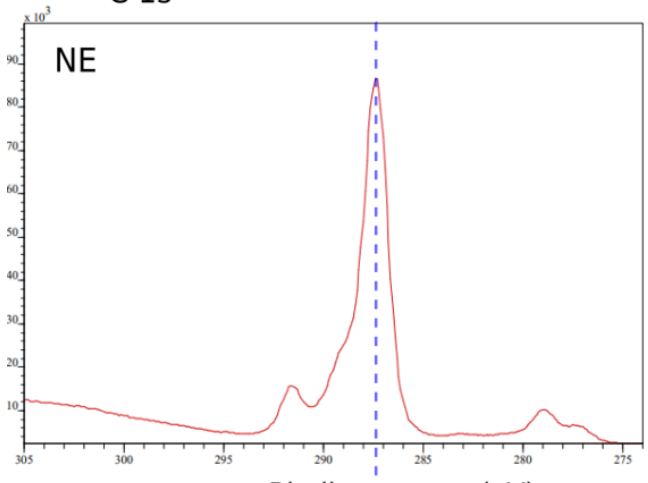

C 1s Binding,'energy (eV)

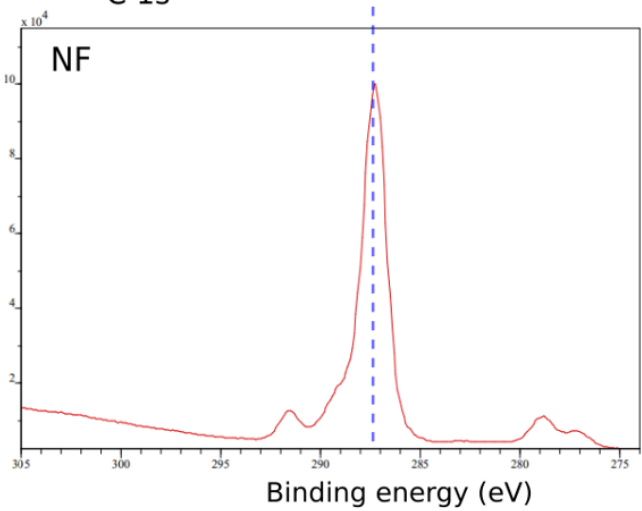

Figure 9. High-resolution XPS spectra of the O 1s (left) and C 1s (right), performed on paper samples.

The XPS spectrum is sensitive to chemical changes related to the way carbon and oxygen bond with various elements. These changes are observed in the binding energy of the carbon and oxygen atoms: the shape of the spectrum is displaced to higher or lower energies depending on the new bonds formed [33,34]. In Figure 9, it can be seen how the chemical environment changes around the carbon and oxygen atoms when the paper samples are aged in NF.

The shape of the XPS spectrum of the oxygen 1s band is the contribution of the $\mathrm{O}^{1-}$ bond energy and the $\mathrm{O}^{2-}$ bond energy, which are very close to each other. Therefore, a widening of this area towards higher energies is an indication of the formation of chemical compounds with a higher content of $\mathrm{O}^{2-}$ bonds. In our case, the signal of the oxygen $1 \mathrm{~s}$ band (shown in the figures at the left) was displaced to higher binding energies in NF-immersed samples, as can be observed by the values of the FWHM of the O 1s band that grows from $2.505 \mathrm{eV}$ for the $\mathrm{NE}$ to $2.63 \mathrm{eV}$ for the NF. The contribution of the oxygen atoms as $\mathrm{O}^{2-}$ increases, making the $\mathrm{O} 1 \mathrm{~s}$ maximum wider. This $\mathrm{O}^{2-}$ contribution is related to bonds that present a high polarization. The observed effect reflects the fact that NPs have bonded to cellulose molecules by substituting $\mathrm{H}$ atoms, which form less polarized bonds with oxygen than the hydroxyl groups of alcohols $(\mathrm{OH})$.

The shape of the XPS spectrum of $\mathrm{C}$ at the 1 s orbital is the contribution of the different saturation grades of carbon bonds in the molecule $(\mathrm{C} 1, \mathrm{C} 2, \mathrm{C} 3 \ldots)$ [35]. In the case of our samples, the change was less noticeable in the carbon binding energies (figures on the right); thus, the carbon bonds were not modified in the aging process.

These changes in the chemical structure of the cellulose are compatible with the hypothesis that NPs bind to the cellulose molecules, preventing the degradation of NE and hindering the advance of the transesterification. In Figure 10, a schematic representation of the chemical interactions that are proposed to explain the interaction between NPs and cellulose molecules within the kraft paper is shown. According to this explanation, the $\mathrm{Fe}_{3} \mathrm{O}_{4} \mathrm{NPs}$ may replace the hydrogen of the alcohol groups. These bonding mechanisms were obtained based on the results of the performed XPS tests. 


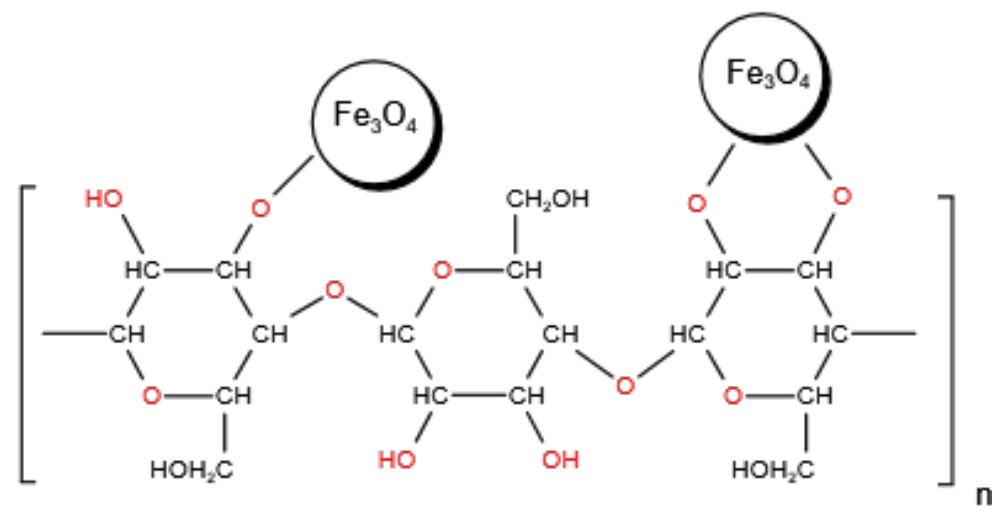

Figure 10. $\mathrm{Fe}_{3} \mathrm{O}_{4} \mathrm{NP}$ binding with cellulose molecules.

\subsection{FTIR Analysis}

The FTIR spectra of some of the NE- and NF-impregnated papers were analyzed to identify the chemical products generated during the accelerated aging process and to confirm the conclusions drawn from XPS tests. In order to compare the aging processes of both types of samples and the influence of the NPs on the aging process, the FTIR spectra of three samples of paper impregnated with NF aged for 6, 30, and 60 days, and equivalent samples impregnated with NE are shown in Figure 11.

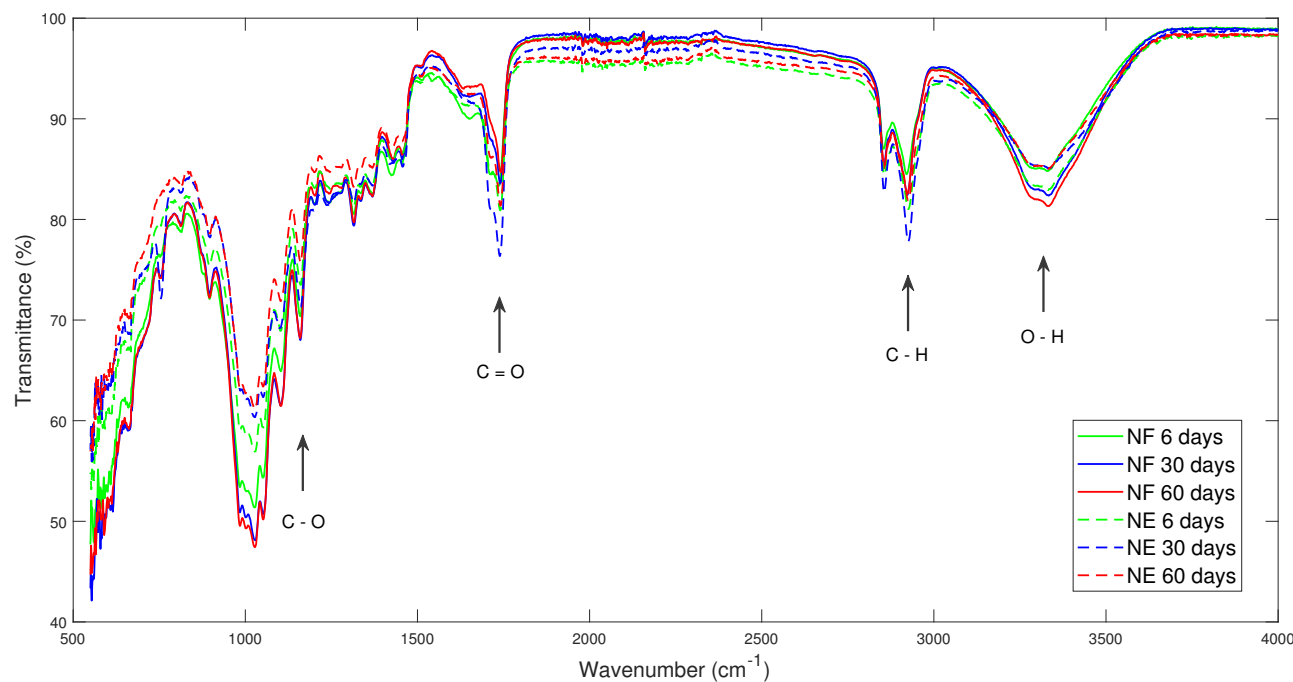

Figure 11. FTIR spectrum of cellulose impregnated with NF and NE, subjected to different aging times.

The first important band that changes from one sample type to another is the one centered around $3450 \mathrm{~cm}^{-1}$. This band corresponds to $\mathrm{O}-\mathrm{H}$ bonds, mostly due to the presence of water molecules and the hydroxyl groups of alcohols of the cellulose, and is always present in cellulose FTIR spectra [36]. In order to improve the observation of the main differences among the spectra of the six samples, a detail of the spectra centered at $3350 \mathrm{~cm}^{-1}$ is plotted in Figure 12. It is possible to observe how the NF-impregnated samples aged for 30 and 60 days present a lower transmittance in this band; this fact is related to the $\mathrm{H}_{2} \mathrm{O}$ molecules generated during the accelerated aging process, and agrees with the observations on the moisture tests presented in Section 3.2. On the other hand, the NE-impregnated samples present a higher transmittance and, in consequence, a lower content of $\mathrm{OH}$ groups, which is in agreement with the hypothesis that water is consumed during the aging process in the presence of NE. 

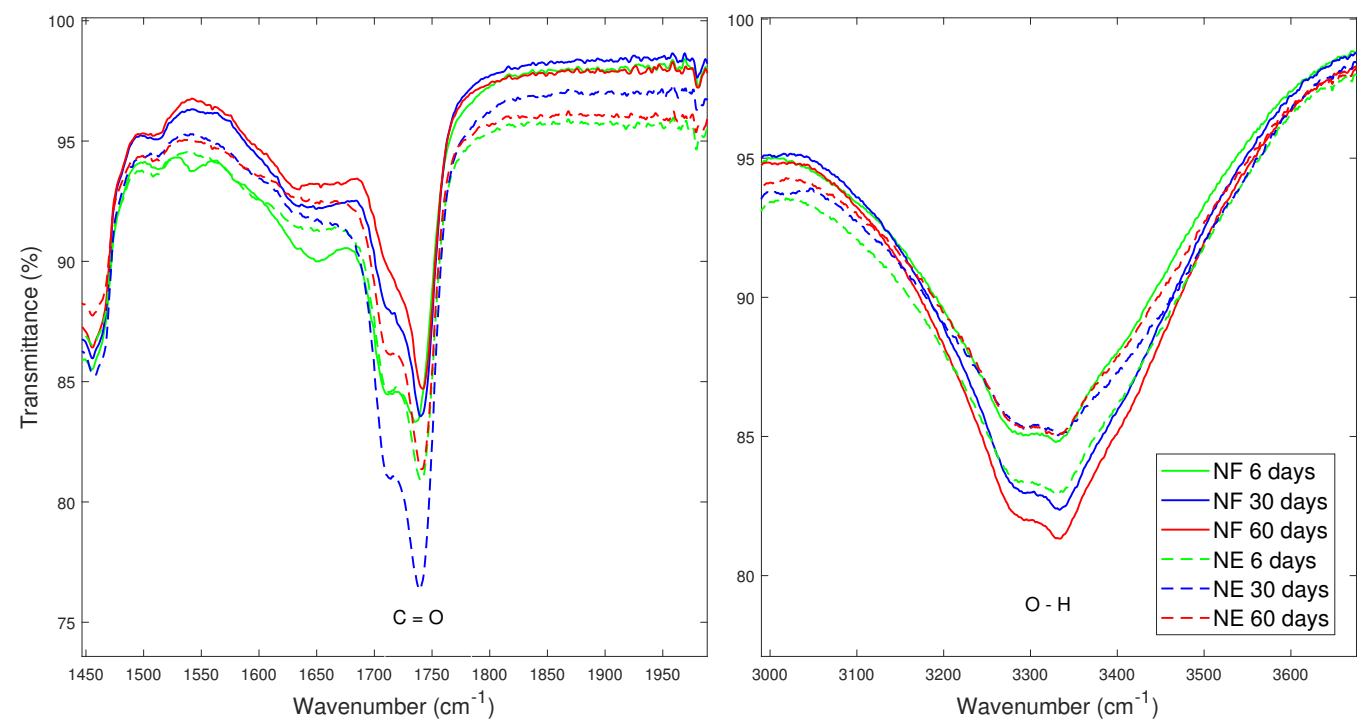

Figure 12. Details of FTIR spectrum of cellulose impregnated with NF and NE, subjected to different aging times.

The band centered around $2800 \mathrm{~cm}^{-1}$ represents the C-H functional groups. As can be seen, the transmittance of the NF-impregnated samples in this band decreased as the aging progressed; this fact is due to the products generated by the hydrolysis of the fatty acids [37]. For the NE-impregnated samples, the evolution was different; the transmittance rose after 30 days of aging and then, for samples of 60 days of aging, decreased to a value almost equal to that of the 6-day aging sample. This fact is consistent with the results of the moisture tests and with the mechanisms proposed in Figures 6 and 7. As the transesterification progresses, it is more likely that water molecules and free fatty acids are consumed in the NE-impregnated samples.

It is easier to differentiate variations in $\mathrm{C}-\mathrm{O}$ and $\mathrm{C}=\mathrm{O}$ functional groups by means of FTIR tests than with XPS tests. The band around wavelength $1700 \mathrm{~cm}^{-1}$ corresponds to the transmittance of the $\mathrm{C}=\mathrm{O}$ functional groups. In Figure 12, a zoom of the spectra centered at $1750 \mathrm{~cm}^{-1}$ is plotted. It is possible to observe how the intensity of the band that represents the $\mathrm{C}=\mathrm{O}$ functional groups changes as the aging progresses; this observation is related with the degradation of fatty acids reported by Frimpong et al. [29]. It can be observed how the NF-impregnated paper presented a lower increase of $\mathrm{C}=\mathrm{O}$ groups in this band as the aging progressed compared with the NE-impregnated samples. This effect could represent better conservation of the insulating system when the cellulose samples are impregnated with NF. The changes of shape in this band also represent how free fatty acids bond to cellulose molecules; this fact is in agreement with previous observations of XPS tests (Figure 9 left).

Finally, in the band around $1000 \mathrm{~cm}^{-1}$, the response of the two types of paper was opposite to that analyzed in the $1000 \mathrm{~cm}^{-1}$ band, with the $\mathrm{C}-\mathrm{O}$ groups turning into $\mathrm{C}=\mathrm{O}$ groups as the aging progressed.

\section{Conclusions}

In the present paper, a variety of tests were performed on samples of paper impregnated with a $\mathrm{Fe}_{3} \mathrm{O}_{4}$-based NF.

As a first conclusion of the present study, it was observed that the TS of kraft paper samples impregnated with NE and NF are very similar. The addition of NP does not affect the rate of loss of mechanical properties of the cellulose, regardless of whether the samples are fresh or aged.

When comparing the results of the moisture tests carried out on the different materials, remarkable differences were observed between the behavior of NF-impregnated samples and NE-impregnated samples. We conclude that the NPs interfere in the degradation mechanisms of the NE and slow down transesterification reactions in the cellulose. This 
hypothesis was confirmed by the XPS and FTIR results, which clearly show a change in the carbon-oxygen bonds of the NF-impregnated samples when compared with those impregnated with the base oil.

We can conclude that NPs affect the aging process of both oil and kraft paper. Some chemical reactions were proposed (mainly transesterification and hydrolysis), but we cannot state which is the most predominant since the oil-paper system allows the mobility of water molecules, meaning that water produced in the paper could be transferred to the oil and trapped by the NPs.

The experimental study will be completed in the future to consider other factors that can impact the aging process, such as the testing temperature, NP concentration, or the base fluid and NPs used to produce the NF.

Author Contributions: Conceptualization, D.P.-R., B.G., J.C.B.; Experimentation D.P.-R.; Original draft preparation, D.P.-R.; review and editing D.P.-R., B.G., J.C.B.; Project administration, resources B.G.; Funding acquisition, resources B.G., J.C.B. All authors have read and agreed to the published version of the manuscript.

Funding: This work was supported by the Spanish State Research Agency under grant PID2019107126RB-C21/ AEI/10.13039/501100011033 and by the Spanish Ministry of Economy and Competitiveness under grant DPI2015-71219-C2-2-R.

Institutional Review Board Statement: Not applicable.

Informed Consent Statement: Not applicable.

Data Availability Statement: Not applicable.

Acknowledgments: The authors acknowledge Adrian Febrero for his support in the lab.

Conflicts of Interest: The authors declare no conflict of interest.

\section{References}

1. Martin, D.; Beckett, C.; Brown, J.; Nielsen, S. Analysis and Mitigation of Australian and New Zealand Power Transformer Failures Resulting in Fires and Explosions. IEEE Electr. Insul. Mag. 2019, 35, 7-14. [CrossRef]

2. Marks, J.; Martin, D.; Saha, T.; Krause, O.; Alibegovic-Memisevic, A.; Russell, G.; Buckley, G.; Chinnarajan, S.; Gibson, M.; MacArthur, T. An Analysis of Australian Power Transformer Failure Modes, and Comparison with International Surveys. In Proceedings of the 2016 Australasian Universities Power Engineering Conference (AUPEC), Brisbane, Australia, 25-28 September 2016; pp. 1-6. [CrossRef]

3. Heathcote, M.J. Basic materials. In J E P Transformer Book; Elsevier: Amsterdam, The Netherlands, 2007. [CrossRef]

4. Wang, X.; Xu, X. Thermal Conductivity of Nanoparticle-fluid Mixture. J. Thermophys. Heat Transf. 1999, 13, 474-480. [CrossRef]

5. Dai, J.; Dong, M.; Li, Y.; Zhou, J. Influence of Nanoparticle Concentration on the Frequency Domain Spectroscopy Properties of Transformer Oil-based Nanofluids. In Proceedings of the 2016 IEEE Conference on Electrical Insulation and Dielectric Phenomena (CEIDP), Toronto, ON, Canada, 16-19 October 2016; pp. 587-590.

6. Kudelcik, J.; Bury, P.; Kopcansky, P.; Timko, M. Dielectric Breakdown in Mineral Oil ITO 100 Based Magnetic Fluid. Phys. Procedia 2010, 9, 78-81. [CrossRef]

7. Yin, W. Niskayuna Nano Dielectric Fluids. U.S. Patent No. 2013/0285781, 31 October 2013.

8. Primo, V.A.; García, B.; Burgos, J.C.; Pérez, D. AC breakdown voltage of Fe3O4 based nanodielectric fluids. Part 1: Analysis of dry fluids. IEEE Trans. Dielectr. Electr. Insul. 2020, 27, 352-359. [CrossRef]

9. Jin, H.; Andritsch, T.; Morshuis, P.H.F.; Smit, J.J. AC breakdown voltage and viscosity of mineral oil based fullerene nanofluids. In Proceedings of the 2013 Annual Report-Conference on Electrical Insulation and Dielectric Phenomena, CEIDP, Shenzhen, China, 20-23 October 2013; pp. 703-706. [CrossRef]

10. Jianzhuo, D.; Ming, D.; Wang, L.; Jianyi, W. Study on AC Breakdown and Broadband Dielectric Response Properties of Transformer Oil-Based Nanofluids. In Proceedings of the International Conference on Condition Monitoring and Diagnosis, Xi'an, China, 25-28 September 2016; pp. 24-27.

11. Shukla, G.; Aiyer, H. Thermal Conductivity Enhancement of Transformer Oil Using Functionalized Nanodiamonds. IEEE Trans. Dielectr. Electr. Insul. 2015, 22, 2185-2190. [CrossRef]

12. Primo, V.A.; García, B.; Burgos, J.C.; Pérez-Rosa, D. Investigation of the Lightning Impulse Breakdown Voltage of Mineral Oil based Fe3O4 Nanofluids. Coatings 2019, 9, 799. [CrossRef]

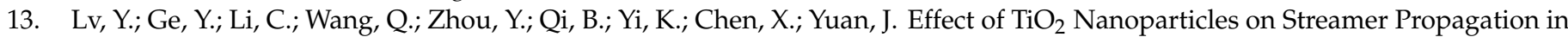
Transformer Oil under Lightning Impulse Voltage. IEEE Trans. Dielectr. Electr. Insul. 2016, 23, 2110-2115. [CrossRef] 
14. Li, J.; Zhang, Z.; Zou, P.; Grzybowski, S.; Zahn, M. Preparation of a vegetable oil-based nanofluid and investigation of its breakdown and dielectric properties. IEEE Electr. Insul. Mag. 2012, 28, 43-50. [CrossRef]

15. Tang, C.; Zhang, S.; Xie, J.; Lv, C. Molecular simulation and experimental analysis of Al2O3-nanoparticle-modified insulation paper cellulose. IEEE Trans. Dielectr. Electr. Insul. 2017, 24, 1018-1026. [CrossRef]

16. Mansour, D.E.A.; Elsaeed, A.M.; Izzularab, M.A. The role of interfacial zone in dielectric properties of transformer oil-based nanofluids. IEEE Trans. Dielectr. Electr. Insul. 2016, 23, 3364-3372. [CrossRef]

17. Liao, R.; Lv, C.; Yang, L.; Zhang, Y.; Wu, W.; Tang, C. The insulation properties of oil-impregnated insulation paper reinforced with nano- $\mathrm{TiO}_{2}$. J. Nanomater. 2013, 2013, 1 . [CrossRef]

18. Pérez-Rosa, D.; García, B.; Burgos, J.C.; Febrero, A. Morphological analysis of transformer Kraft paper impregnated with dielectric nanofluids. Cellulose 2020, 27, 8963-8975. [CrossRef]

19. Liu, D.; Guo, Z.; DIng, J.; Xu, X. Thermal Aging Effect on Properties of Pure and Doped Nano-TiO ${ }_{2}$ Cellulose Pressboard. IEEE Trans. Dielectr. Electr. Insul. 2021, 28, 133-141. [CrossRef]

20. Sun, P.; Sima, W.; Jiang, X.; Zhang, D.; He, J.; Chen, Q. Failure of nano-modified oil impregnated paper under repeated impulse voltage: Effects of $\mathrm{TiO}_{2}$ nanoparticles on space charge characteristics. IEEE Trans. Dielectr. Electr. Insul. 2018, 25, $2103-2111$. [CrossRef]

21. Pérez-Rosa, D.; García, B.; Burgos, J.C. Dielectric Response of the Oil-Paper Insulation System in Nanofluid-Based Transformers IEEE Access 2021, 9, 83797-83805. [CrossRef]

22. Cimbala, R.; Bucko, S.; Kruželák, L.; Kosterec, M. Thermal Degradation of Transformer Pressboard Impregnated with Magnetic Nanofluid Based on Transformer Oil. In Proceedings of the 2017 18th International Scientific Conference on Electric Power Engineering (EPE), Kouty nad Desnou, Czech Republic, 17-19 May 2017; pp. 1-5.

23. Swati, K.; Sarathi, R.; Sharma, K.S. Understanding the surface discharge activity with thermally aged nanofluid impregnated paper insulating material. Int. J. Electr. Eng. Inform. 2017, 9, 762-775. [CrossRef]

24. Maharana, M.; Baruah, N.; Nayak, S.K.; Sahoo, N. Nanofluid and Transformer Oil Impregnated Aged Kraft Paper: Analysis of its Mechanical Strength. In Proceedings of the 2018 IEEE PES Asia-Pacific Power and Energy Engineering Conference (APPEEC), Kota Kinabalu, Malaysia, 7-10 October 2018; pp. 302-305. [CrossRef]

25. Maharana, M.; Baruah, N.; Nayak, S.K.; Meher, N.; Iyer, P.K. Condition Assessment of Aged Ester-Based Nanofluid Through Physicochemical and Spectroscopic Measurement. IEEE Trans. Instrum. Meas. 2019, 68, 4853-4863. [CrossRef]

26. Ibrahim, A.; Nasrat, L.; Elnoby, A.; Eldebeiky, S. Thermal ageing study of ZnO nanofluid-cellulose insulation. IET Nanodielectr 2020, 3, 124-130. [CrossRef]

27. Primo, V.A.; Pérez-Rosa, D.; García, B.; Cabanelas, J.C. Evaluation of the Stability of Dielectric Nanofluids for Use in Transformers under Real Operating Conditions. Nanomaterial 2019, 9, 143. [CrossRef]

28. ASTM International. Standard Test Method for Tensile Properties of Paper and Paperboard Using Constant-Rate-of-Elongation Apparatus; 19428-2959 USA; ASTM International: West Conshohocken, PA, USA, 16 August 2017. [CrossRef]

29. Frimpong, G.K.; Oommen, T.V.; Asano, R. A survey of aging characteristics of cellulose insulation in natural ester and mineral oil. IEEE Electr. Insul. Mag. 2011, 27, 36-48. [CrossRef]

30. TF D1.01.09. Cigré Brochure 254. Dielectric response methods for diagnostics of power transformers. Electra 2004, 33, 23-34.

31. García, B.; García, T.; Primo, V.; Burgos, J.C.; Urquiza, D. Studying the loss of life of natural-ester-filled transformer insulation: Impact of moisture on the aging rate of paper. IEEE Electr. Insul. Mag. 2017, 33, 15-23. [CrossRef]

32. Oommen, T.V.; Raleigh, N.C.; Claiborne, C.C.; Pa, S. Electrical Transformers Containing Electrical Insulating Fluids Comprising High Oleic Acid Oil Compositions. U.S. Patent 5949017, 7 September 1999; pp. 4-7.

33. Yang, L.; Liao, R.; Caixin, S.; Zhu, M. Influence of vegetable oil on the thermal aging of transformer paper and its mechanism. IEEE Trans. Dielectr. Electr. Insul. 2011, 18, 692-700. [CrossRef]

34. Beldar, S.; Dolasiya, R.; Morde, G.; Narasimhan, C. FTIR and X-Ray photoelectron spectral (XPS) evidence for interaction between natural ester and cellulose paper. In Proceedings of the 2019 IEEE 20th International Conference on Dielectric Liquids (ICDL), Roma, Italy, 23-27 June 2019; pp. 1-4. [CrossRef]

35. Junior de Menezes, A.; Siqueira, G.; Curvelo, A.A.; Dufresne, A. Extrusion and characterization of functionalized cellulose whiskers reinforced polyethylene nanocomposites. Polymer 2009, 50, 4552-4563. [CrossRef]

36. Oh, S.Y.; Yoo, D.I.; Shin, Y.; Seo, G. FTIR analysis of cellulose treated with sodium hydroxide and carbon dioxide. Carbohydr. Res. 2005, 340, 417-428. [CrossRef] [PubMed]

37. Munajad, A.; Subroto, C.; Suwarno. Study on the effects of thermal aging on insulating paper for high voltage transformer composite with natural ester from palm oil using fourier transform infrared spectroscopy (ftir) and energy dispersive X-ray spectroscopy (EDS). Energies 2017, 10, 1857. [CrossRef] 